\title{
Keywords reflecting sepsis presentation based on mode of emergency department arrival: a retrospective cross-sectional study
}

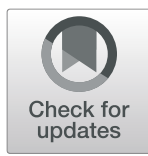

Ulrika Margareta Wallgren ${ }^{1,2,3} \mathbb{D}^{\mathbb{D}}$, Eric Larsson ${ }^{3}$, Anna Su$^{1,4}$, Jennifer Short ${ }^{1,5}$, Hans Järnbert-Pettersson ${ }^{1}$ and Lisa Kurland ${ }^{1,3,6^{*}}$

\begin{abstract}
Background: Current sepsis screening tools are predominantly based on vital signs. However, patients with serious infections frequently present with normal vital signs and there has been an increased interest to include other variables such as symptoms in screening tools to detect sepsis. The majority of patients with sepsis arrive to the emergency department by emergency medical services. Our hypothesis was that the presentation of sepsis, including symptoms, may differ between patients arriving to the emergency department by emergency medical services and patients arriving by other means. This information is of interest to adapt future sepsis screening tools to the population in which they will be implemented. The aim of the current study was to compare the prevalence of keywords reflecting the clinical presentation of sepsis based on mode of arrival among septic patients presenting to the emergency department.
\end{abstract}

Methods: Retrospective cross-sectional study of 479 adult septic patients. Keywords reflecting sepsis presentation upon emergency department arrival were quantified and analyzed based on mode of arrival, i.e., by emergency medical services or by other means. We adjusted for multiple comparisons by applying Bonferroni-adjusted significance levels for all comparisons. Adjustments for age, gender, and sepsis severity were performed by stratification. All patients were admitted to the emergency department of Södersjukhuset, Stockholm, and discharged with an ICD-10 code compatible with sepsis between January 1, and December 31, 2013.

Results: "Abnormal breathing" (51.8\% vs 20.5\%, $p$ value < 0.001 ), "abnormal circulation" (38.4\% vs 21.3\%, $p$ value < 0.001), "acute altered mental status" (31.1\% vs 13.1\%, $p$ value $<0.001$ ), and "decreased mobility" (26.1\% vs $10.7 \%, p$ value $<0.001)$ were more common among patients arriving by emergency medical services, while "pain" $(71.3 \%$ vs $40.1 \%, p$ value $<0.001)$ and "risk factors for sepsis" (50.8\% vs 30.8\%, $p$ value $<0.001)$ were more common among patients arriving by other means.

Conclusions: The distribution of most keywords related to sepsis presentation was similar irrespective of mode of arrival; however, some differences were present. This information may be useful in clinical decision tools or sepsis screening tools.

Keywords: Emergency medical service, Emergency care, Emergency department, Sepsis, Symptoms

\footnotetext{
* Correspondence: lisa.kurland@oru.se

'Department of Clinical Science and Education, Karolinska Institutet,

Söderssjukhuset, Sjukhusbacken 10, 11883 Stockholm, Sweden

${ }^{3}$ Department of Medical Sciences, Örebro University, Campus USÖ, Södra

Grev Rosengatan 32, 70112 Örebro, Sweden

Full list of author information is available at the end of the article
}

C C The Author(s). 2021 Open Access This article is licensed under a Creative Commons Attribution 4.0 International License, which permits use, sharing, adaptation, distribution and reproduction in any medium or format, as long as you give appropriate credit to the original author(s) and the source, provide a link to the Creative Commons licence, and indicate if changes were made. The images or other third party material in this article are included in the article's Creative Commons licence, unless indicated otherwise in a credit line to the material. If material is not included in the article's Creative Commons licence and your intended use is not permitted by statutory regulation or exceeds the permitted use, you will need to obtain permission directly from the copyright holder. To view a copy of this licence, visit http://creativecommons.org/licenses/by/4.0/ The Creative Commons Public Domain Dedication waiver (http://creativecommons.org/publicdomain/zero/1.0/) applies to the data made available in this article, unless otherwise stated in a credit line to the data. 


\section{Background}

Sepsis, defined as life-threatening organ dysfunction caused by a dysregulated host response to infection [1], is one of the most common medical emergencies and affects approximately 19 million people worldwide each year [2]. Septic patients are in need of urgent medical care and early treatment requires early identification. However, sepsis is often difficult to identify due to a wide variety of presenting symptoms $[3,4]$.

Most screening tools designed to identify sepsis within emergency care are based on vital signs alone $[5,6]$ despite the fact that one-third of all patients with severe infection present with normal vital signs [7]. Therefore, one may conclude that variables other than vital signs need to be considered in addition to vital signs in order to increase the identification of the septic patient.

Keywords related to septic patients' symptom presentation have previously been shown to follow a pattern among septic patients presenting to the emergency medical services (EMS), [3]. However, septic patients arriving to the emergency department (ED) by EMS have previously been shown to present with a more severe condition than patients arriving by other means [8]. Hence, we are interested in understanding whether the presentation of sepsis differs depending on mode of ED arrival.

The aim of the current study was to compare the prevalence of keywords reflecting the clinical presentation and mode of arrivalamong septic patients presenting to the emergency department

\section{Methods}

\section{Study design and setting}

This was a retrospective cross-sectional study of 479 adult patients admitted to the ED of Södersjukhuset between January 1, and December 31, 2013, and discharged with an International Classification of Disease, tenth revision (ICD-10) code compatible with sepsis.

The ED of Södersjukhuset is an urban 603-bed teaching hospital in Stockholm, Sweden, with more than 129,000 adult ED visits annually [9].

\section{Selection of study participants Inclusion criteria}

Adult patients ( $\geq 18$ years of age) admitted from the ED to in-hospital care at Södersjukhuset that upon discharge from in-hospital care received an ICD-10 code (primary and/or secondary diagnosis) compatible with sepsis (A02.1, A22.7, A26.7, A32.7, A39.2, A39.4, A40.0-A40.3, A48-A49, A41.0-A41.5, A41.8-A41.9, A42.7, B37.7, R57.2, R65.0-65.1) were included. Also, patients that died during in-hospital care were included in the current study.

\section{Exclusion criteria}

Exclusion criteria were (1) healthcare-associated infections (HCAI), defined as sepsis with an onset $\geq 48 \mathrm{~h}$ after admission to the ED [10], (2) EMS transport of patients already being treated for sepsis or an infection, (3) unknown mode of arrival, and (4) lack of ED and/or EMS record.

\section{Definitions}

Sepsis was defined as discharge from in-hospital care with an ICD-10 code compatible with sepsis (see the "Inclusion criteria" section above). The study material was collected during the period when the Sepsis- 2 criteria [11] were in use.

Severe sepsis was defined, in accordance to a previously developed definition adapted to emergency care [12], see Additional file 1.

The EMS group was defined as patients arriving to the ED by EMS, i.e., ambulance or ambulance helicopter. The non-EMS group was defined as patients arriving to the ED by any means of transportation other than EMS, i.e., walking, by private car/taxi, or police transport.

\section{Keywords}

Primary keywords were defined as symptoms or factors that describe the septic patient's clinical presentation in the ED setting, e.g., "vomiting," "fever," or "hypotension." The combined keywords consist of several primary and/ or combined keywords. The primary and combined keywords were those identified in a previous study among Swedish EMS patients [5] with the addition of any new keyword describing the patient's clinical presentation in the ED, i.e., not previously identified in the prior prehospital study [3].

\section{Study protocol}

Keywords reflecting clinical presentation were quantified, both as primary keywords and as combined keywords within two subgroups of patients based on mode of arrival: by EMS or by means of transportation other than EMS.

ED and in-hospital records were reviewed (TakeCare ${ }^{\odot}$ v. 18.3.10 CompuGroup Medical Stockholm Sweden) and analyzed with respect to prevalence of keywords mode of arrival and demographics (age gender and sepsis severity)

The chief complaint, current history, and preliminary assessment sections of the ED charts were analyzed for the quantification of keywords. The current history section focuses on the acute situation and not a comprehensive medical history. Only symptoms with new onset, defined as onset within 3 weeks prior to ED arrival, were considered relevant for the current study. Each patient 
could fulfill multiple primary and several different combined keywords.

\section{Data analysis}

The statistical analysis program SPSS ${ }^{\circ}$ (Statistical Package for Social Sciences $\mathrm{SPSS}^{\circ}$, $\mathrm{IBM}^{\oplus}$, student version 22.0) was used to analyze the prevalence of keywords. Independent-samples $T$ test was used to compare means and Chi-square test was used to compare proportions between patients arriving by EMS with those of patients arriving by other means (1) in the entire group of septic ED patients and (2) in strata based on age, gender, and severity of sepsis (severe vs non-severe sepsis) to adjust for possible differences between the EMS vs non-EMS groups due to these factors. Fischer's exact test was used when the expected cell count was $<5$.

$P$ values are presented without adjustment for multiple comparisons and the Bonferroni-adjusted significance level is described in the footnote of each table by dividing the significance level 0.05 with the number of performed comparisons. Only two tailed $P$ values that remained significant according to the Bonferroniadjusted significance level are considered significant in the current study.

\section{Ethical approval}

Stockholm Regional Ethical Review Board approval was obtained for this study (reference number 2012/1288$31 / 3)$.

\section{Results}

\section{Patient characteristics}

See Fig. 1 for flow chart for inclusion and exclusion of patients.

A total of 479 patients were included in current study: 357 EMS patients and 122 non-EMS patients.

Characteristics of the patients are presented in Table 1. The median age in the entire sample of septic ED patients was 75 years (Interquartile range, IQR 61-85), 255/479 (53.2\%) were men and 248/459 $(54.0 \%)$ with sufficient documentation to determine severity grade had severe sepsis. The overall inhospital mortality was $99 / 479$ (20.7\%).

The median age in the EMS group was 15.5 years older than in the non-EMS group (78.0 years; IQR $68-86$ vs 62.5 years; IQR $39-73, p$ value $<0.001)$. Patients in the EMS group had a significantly higher prevalence of severe sepsis than patients in the non-EMS group (218/ $346 ; 63.0 \%$ vs $30 / 113 ; 26.5 \%, p$ value $<0.001)$ and a higher in-hospital mortality rate $(94 / 357 ; 26.3 \%$ vs $5 /$ $122 ; 4.1 \%, p$ value $<0.001)$. There was no significant difference with respect to gender between the patients arriving by EMS vs non-EMS, see Table 1 .

\section{Keywords}

Ninety primary keywords and 14 combined keywords describing the presentation of septic patients were extracted from ED charts, see Additional files 2 and 3.

\section{Primary keywords}

The prevalence of primary keywords in the entire sample of septic patients and among patients arriving by EMS and non-EMS respectively is presented in Additional file 2 .

Five new keywords were identified in the ED setting which were not present in the former study based in the prehospital setting [5]. These were "rash," "sensitivity to sound," "photosensitivity," "blisters (on skin)," and "pale stool." All five had a prevalence below or equal to 3/479 patients (0.6\%), see Additional file 2.

\section{Combined keywords}

The prevalence of combined keywords in the entire sample of septic patients, and based on mode of arrival, is presented in Additional file 3.

\section{All keywords exceeding a prevalence of $20 \%$}

The prevalence of all keywords (both primary and combined) exceeding $20 \%$ in the entire sample of septic patients and based on mode of arrival is presented in Table 2.

All septic patients Twelve keywords (primary and combined) reflecting septic patients' presentation exceeded a prevalence of $20 \%$ in the entire sample of 479 patients: "abnormal, or suspected abnormal temperature" $(n=$ $319,66.6 \%)$, "pain" ( $n=230,48.0 \%)$, "abnormal breathing" ( $n=210,43.8 \%)$, "risk factors for sepsis" ( $n=172$, $35.9 \%)$, "abnormal circulation" ( $n=163,34.0 \%)$, "temporal deterioration" ( $n=144,30.1 \%)$, "gastrointestinal symptoms" $(n=137,28.6 \%)$, "acute altered mental status" ( $n=127,26.5 \%)$, "abnormal skin" ( $n=125,26.1 \%)$, "abnormal urination" ( $n=118,24.6 \%)$, "loss of energy" ( $n=113,23.6 \%)$, and "decreased mobility" $(n=106$, 22.1\%), see Table 2 .

Comparison between all keywords with a prevalence exceeding 20\% Four keywords (primary and combined) with a prevalence exceeding $20 \%$ in the entire sample of septic patients were significantly more frequent in the EMS group than in the non-EMS group: "abnormal breathing" $(185 / 357 ; 51.8 \%$ vs $25 / 122 ; 20.5 \%, p$ value < 0.001 ), "abnormal circulation” (137/357; $38.4 \%$ vs $26 / 122$; $21.3 \%, p$ value $<0.001$ ), "acute altered mental status" $(111 / 357 ; 31.1 \%$ vs $16 / 122 ; 13.1 \%, p$ value $<0.001)$ and "decreased mobility" (93/357; 26.1\% vs $13 / 122 ; 10.7 \%, p$ value $<0.001)$, see Table 2 . 


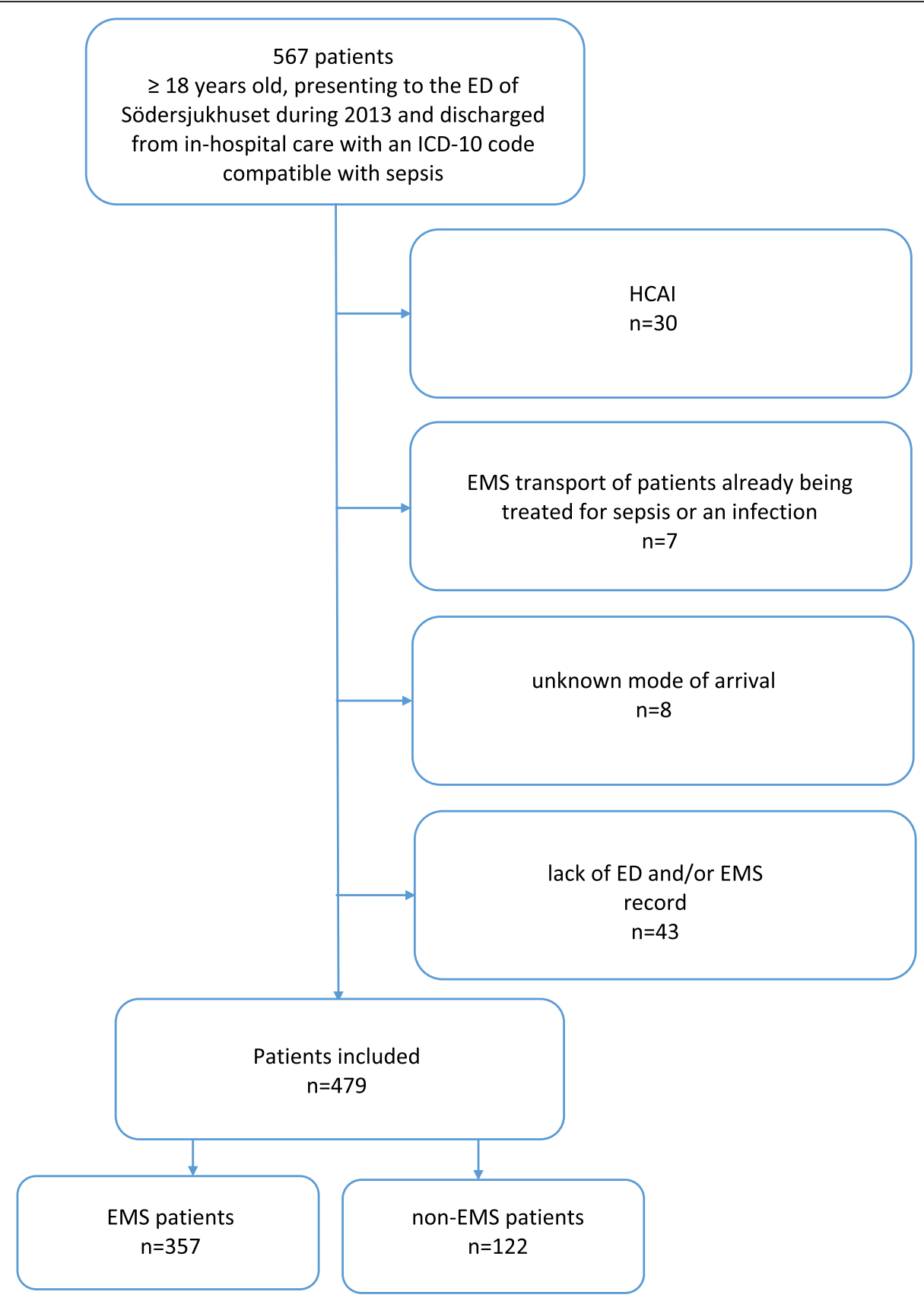

Fig. 1 Flow chart for inclusion and exclusion of adult patients arriving to the ED of Södersjukhuset during 2013 and discharged with ICD code sepsis. EMS, emergency medical services; ED, emergency department; ICD, International Classification of Disease; HCAl,

healthcare-associated infections

Two keywords with a prevalence exceeding $20 \%$ in the entire sample of septic patients were significantly more frequent in the non-EMS group than in the EMS group: "pain" (87/122; $71.3 \%$ vs $143 / 357 ; 40.1 \%, p$ value $<0.001)$ and "risk factors for sepsis" (62/122; $50.8 \%$ vs 110/357; $30.8 \%, p$ value $<0.001)$, see Table 2 .

Stratification analyses based on age, gender, and sepsis severity are presented in Additional files 4, 5, and 6.

\section{Discussion}

The most frequent keywords reflecting clinical presentation in the entire sample of septic patients arriving to the ED were "abnormal, or suspected abnormal temperature," "pain," "abnormal breathing," "risk factors for sepsis," "abnormal circulation," "temporal deterioration," "gastrointestinal symptoms," "acute altered mental status," "abnormal urination," "loss of energy," and 
Table 1 Characteristics of the patients with community-acquired sepsis presenting to the ED of Södersjukhuset during $2013^{*}$

\begin{tabular}{|c|c|c|c|c|c|c|c|}
\hline \multirow[b]{2}{*}{ Variable } & \multicolumn{2}{|c|}{ Entire sample of septic patients, $N=479$} & \multicolumn{2}{|c|}{ EMS group, $n=357$} & \multicolumn{2}{|c|}{ non-EMS group, $n=122$} & \multirow{2}{*}{$\begin{array}{l}P \\
\text { value }\end{array}$} \\
\hline & Median (IQR) & Number (\%) & Median (IQR) & Number (\%) & Median (IQR) & Number (\%) & \\
\hline Age, years & $75(61-85)$ & & $78.0(68-86)$ & & $62.5(39-73)$ & & $<0.001$ \\
\hline \multicolumn{8}{|l|}{ Age groups } \\
\hline$<65$ years & & 137/479 (28.6) & & $69 / 357(19.3)$ & & $68 / 122(55.7)$ & \\
\hline $65-74$ years & & $102 / 479(21.3)$ & & $76 / 357(21.3)$ & & 26/122 (21.3) & \\
\hline$\geq 75$ years & & $240 / 479(50.1)$ & & 212/357 (59.4) & & 28/122 (23.0) & \\
\hline \multicolumn{8}{|l|}{ Gender } \\
\hline Male & & $255 / 479(53.2)$ & & 196/357 (54.9) & & $59 / 122(48.4)$ & 0.211 \\
\hline Severe sepsis & & $248 / 459^{* * *}(54.0)$ & & $218 / 346^{* * *}(63.0)$ & & $30 / 113^{* *}(26.5)$ & $<0.001$ \\
\hline In-hospital mortality & & $99 / 479(20.7)$ & & $94 / 357(26.3)$ & & $5 / 122(4.1)$ & $<0.001$ \\
\hline
\end{tabular}

ED emergency department, IQR interquartile range, EMS emergency medical services

*The table illustrates characteristics of the entire population of patients admitted to the ED of Södersjukhuset during 2013 and discharged with an ICD-10 code compatible with sepsis, in addition to characteristics based on mode of arrival

***Number of patients with sufficient documentation to determine whether severe sepsis or not

"decreased mobility." Keywords more common among septic patients arriving by EMS were "abnormal breathing," "abnormal circulation," "acute altered mental status," and "decreased mobility" while "pain" and "risk factors for sepsis" were more frequent among septic patients arriving to the ED by means other than EMS.

\section{Keywords with a similar prevalence among patients arriving by EMS and non-EMS}

The most common combined keyword among both patients arriving by EMS and by non-EMS was "abnormal, or suspected abnormal temperature." Both fever and hypothermia have previously been described as symptoms related to the septic patient $[3,13]$. However, despite "abnormal, or suspected abnormal temperature" being the most prevalent keyword in the current study, approximately one-third of the included patients did not present with fever. This finding is consistent with previous studies [3, 14].

"Temporal deterioration" represents an acute change in the patient's habitual state, but it does not describe the details of this change. The prevalence of temporal deterioration was high both among EMS and non-EMS patients. These findings are consistent with those demonstrated by Bohm et al. in emergency calls involving septic patients [15].

Vomiting and diarrhea were common among both patients arriving by EMS and by non-EMS. The high frequency of "gastrointestinal symptoms" in the current study is supported by previous studies [3, 13].

The keywords "abnormal skin," "abnormal urination," and "loss of energy" were also present among patients arriving by both EMS and by non-EMS to a similar extent.
Keywords more frequent among patients arriving by EMS "Abnormal circulation," "abnormal breathing," "acute altered mental status," and "decreased mobility" were all significantly more common among patients arriving by EMS. The first three are directly connected to the former criteria for severe sepsis [11] and the findings most likely reflect that EMS patients are more severely ill than non-EMS patients, which is also supported by previous studies [8].

\section{Keywords more frequent among patients not arriving by EMS}

"Pain" is an unspecific symptom and the single most common chief complaint among ED patients in general [16]. That pain was more common among non-EMS patients could potentially be a consequence of the increased prevalence of acute altered mental status among patients arriving by EMS, in turn impairing the patient's capability to express pain. Furthermore, keywords reflecting abnormal vital signs were more common among patients arriving by EMS patients and abnormal vital signs may render more attention among emergency care providers as compared to symptoms, e.g., pain.

The combined keyword "risk factors for sepsis" includes several primary keywords such as ongoing or recent infection/invasive procedures/immunosuppressive treatment but did not include traditional risk factors for sepsis such as age and pre-existing comorbidity. However, traditional risk factors should be considered in a future screening tool. The current study included components registered in the chief complaint, current history, and preliminary assessment sections of the ED charts, where the current history section focuses on the acute situation and not a comprehensive medical history, e.g., pre-existing comorbidity. Patients with "risk factors 
Table 2 Prevalence of keywords exceeding 20\% among ED patients discharged with ICD-10 code sepsis

\begin{tabular}{|c|c|c|c|c|c|c|c|c|}
\hline \multirow[t]{3}{*}{ Order } & \multirow[t]{3}{*}{ Keyword [5] } & \multicolumn{6}{|c|}{ Prevalence } & \multirow{3}{*}{$\begin{array}{l}P \\
\text { value } * *\end{array}$} \\
\hline & & \multicolumn{2}{|c|}{$\begin{array}{l}\text { Entire sample of ED } \\
\text { patients }(N=479)\end{array}$} & \multicolumn{2}{|c|}{$\begin{array}{l}\text { EMS group } \\
(n=357)\end{array}$} & \multicolumn{2}{|c|}{$\begin{array}{l}\text { non-EMS group } \\
(n=122)\end{array}$} & \\
\hline & & Number & $\begin{array}{l}\text { Percent } \\
\text { (\%) and } \\
95 \% \mathrm{Cl}\end{array}$ & Number & $\begin{array}{l}\text { Percent } \\
\text { (\%) and } \\
95 \% \mathrm{Cl}\end{array}$ & Number & $\begin{array}{l}\text { Percent } \\
\text { (\%) and } \\
95 \% \mathrm{Cl}\end{array}$ & \\
\hline 1 & $\begin{array}{l}\text { Abnormal, or suspected abnormal temperature } \\
\text { In turn including primary keywords shivering OR hypothermia } \\
\text { OR the following combined keywords: Confirmed or } \\
\text { suspected fever, confirmed abnormal temperature (confirmed } \\
\text { fever or hypothermia) }\end{array}$ & 319 & $\begin{array}{l}66.6(62.3- \\
70.7)\end{array}$ & 232 & $\begin{array}{l}65.0(60.0- \\
69.8)\end{array}$ & 87 & $\begin{array}{l}71.3(62.7- \\
78.6)\end{array}$ & 0.201 \\
\hline 2 & $\begin{array}{l}\text { Pain } \\
\text { Abdominal/extremity/back/undefined/urinary tract/joint/ } \\
\text { chest/general/headache/throat/wound/painful muscle cramp/ } \\
\text { positive Pasternatsy's sign (costovertebral angle tenderness) }\end{array}$ & 230 & $\begin{array}{l}48.0(43.6- \\
52.5)\end{array}$ & 143 & $\begin{array}{l}40.1(35.1- \\
45.2)\end{array}$ & 87 & $\begin{array}{l}71.3(62.7- \\
78.6)\end{array}$ & $<0.001$ \\
\hline 3 & $\begin{array}{l}\text { Abnormal breathing } \\
\text { Tachypnea, low oxygen saturation, airway secretions, } \\
\text { breathing difficulties, cough, or obstructive breathing }\end{array}$ & 210 & $\begin{array}{l}43.8(39.5- \\
48.3)\end{array}$ & 185 & $\begin{array}{l}51.8(46.7- \\
57.0)\end{array}$ & 25 & $\begin{array}{l}20.5(14.3- \\
28.5)\end{array}$ & $<0.001$ \\
\hline 4 & $\begin{array}{l}\text { Risk factors for sepsis } \\
\text { Known ongoing or recent infection, current antibiotic } \\
\text { treatment, recent invasive procedures, substance abuse, } \\
\text { compromised immune system, chronically compromised } \\
\text { breathing }\end{array}$ & 172 & $\begin{array}{l}35.9(31.7- \\
40.3)\end{array}$ & 110 & $\begin{array}{l}30.8(26.3- \\
35.8)\end{array}$ & 62 & $\begin{array}{l}50.8(42.1- \\
59.5)\end{array}$ & $<0.001$ \\
\hline 5 & $\begin{array}{l}\text { Abnormal circulation } \\
\text { Weak pulse or difficulties to palpate the pulse, peripheral } \\
\text { coldness, cardiac arrest, tachycardia, low blood pressure, } \\
\text { prolonged capillary refill time or non-measurable circulatory } \\
\text { variables }\end{array}$ & 163 & $\begin{array}{l}34.0(29.9- \\
38.4)\end{array}$ & 137 & $\begin{array}{l}38.4(33.5- \\
43.5)\end{array}$ & 26 & $\begin{array}{l}21.3(15.0- \\
29.4)\end{array}$ & 0.001 \\
\hline 6 & $\begin{array}{l}\text { Temporal deterioration } \\
\text { Stated deterioration or expressions describing a temporal } \\
\text { change }\end{array}$ & 144 & $\begin{array}{l}30.1 \\
(26.1--34.3)\end{array}$ & 102 & $\begin{array}{l}28.6(24.1- \\
33.5)\end{array}$ & 42 & $\begin{array}{l}34.4(26.6- \\
43.2)\end{array}$ & 0.223 \\
\hline 7 & $\begin{array}{l}\text { Gastrointestinal symptoms } \\
\text { Vomiting, diarrhea, reduced amount of stool, gastrointestinal } \\
\text { bleeding, obstipation, pale feces }\end{array}$ & 137 & $\begin{array}{l}28.6(24.7- \\
32.8)\end{array}$ & 104 & $\begin{array}{l}29.1(24.7- \\
34.1)\end{array}$ & 33 & $\begin{array}{l}27.0(20.0- \\
35.5)\end{array}$ & 0.660 \\
\hline 8 & $\begin{array}{l}\text { Acute altered mental status } \\
\text { Abnormal behavior or level of consciousness (excluding } \\
\text { previously known dementia or mental retardation without } \\
\text { statement worse) OR abnormal verbal response defined as } \\
\text { no/decreased verbal response }\end{array}$ & 127 & $\begin{array}{l}26.5\left(22.8^{-}\right. \\
30.6)\end{array}$ & 111 & $\begin{array}{l}31.1(26.5- \\
36.1)\end{array}$ & 16 & $\begin{array}{l}13.1(8.2- \\
20.2)\end{array}$ & $<0.001$ \\
\hline 9 & $\begin{array}{l}\text { Abnormal skin } \\
\text { Paleness, wounds or wound infection, sweaty, cyanosis, } \\
\text { redness, icterus, mottling, bruises, rash, blisters, or peteckiae, } \\
\text { change of skin turgor, exuding skin }\end{array}$ & 125 & $\begin{array}{l}26.1(22.4- \\
30.2)\end{array}$ & 96 & $\begin{array}{l}26.9(22.6- \\
31.7)\end{array}$ & 29 & $\begin{array}{l}23.8(17.1- \\
32.1)\end{array}$ & 0.498 \\
\hline 10 & $\begin{array}{l}\text { Abnormal urination } \\
\text { Abnormal urination (such as hematuria without trauma, bad } \\
\text { smelling or cloudy urine, increased frequency of urination) OR } \\
\text { urinary tract pain OR decreased urinary volumes OR } \\
\text { dysfunction of urinary catheters defined as obstruction/ } \\
\text { leakage/problematic urinary catheters including nefrostomias }\end{array}$ & 118 & $\begin{array}{l}24.6(21.0- \\
28.7)\end{array}$ & 92 & $\begin{array}{l}25.8(21.5- \\
30.6)\end{array}$ & 26 & $\begin{array}{l}21.3(15.0- \\
29.4)\end{array}$ & 0.324 \\
\hline 11 & $\begin{array}{l}\text { Loss of energy } \\
\text { Defined as fatigue, weakness, faintness or similar expressions }\end{array}$ & 113 & $\begin{array}{l}23.6(20.0- \\
27.6)\end{array}$ & 91 & $\begin{array}{l}25.5(21.3- \\
30.3)\end{array}$ & 22 & $\begin{array}{l}18.0(12.2- \\
25.8)\end{array}$ & 0.094 \\
\hline 12 & $\begin{array}{l}\text { Decreased mobility } \\
\text { in turn including primary keywords remained sitting or lying } \\
\text { in an abnormal way OR decreased miscellaneous mobility OR } \\
\text { the following combined keywords: "weakness of the legs" and } \\
\text { "fallen or being found on the floor" }\end{array}$ & 106 & $\begin{array}{l}22.1(18.6- \\
26.1)\end{array}$ & 93 & $\begin{array}{l}26.1(21.8- \\
30.8)\end{array}$ & 13 & $\begin{array}{l}10.7(6.3- \\
17.4)\end{array}$ & $\begin{array}{l}< \\
0.001\end{array}$ \\
\hline
\end{tabular}

ED emergency department, EMS emergency medical services, $\mathrm{Cl}$ confidence interval

*The prevalence of all keywords (both primary and combined) exceeding $20 \%$ in the entire sample of patients admitted to the ED of Södersjukhuset during 2013 and discharged with an ICD-10 code compatible with sepsis. The table illustrates the prevalence in the entire group and the prevalence based on mode of arrival **For comparison between EMS and non-EMS groups. $P$ values are presented without adjustment for multiple comparisons. In total 13 tests were performed. Bonferroni-adjusted significance level is $0,05 / 13=0,0038$. $P$ values indicating significant differences after adjustment for multiple comparisons by Bonferroni correction are bolded and considered significant in the current study 
for sepsis," as defined in the current study, are often informed to seek medical attention if they deteriorate and may therefore seek medical attention at an earlier stage and hence need an ambulance to a lesser extent. In addition, patients with "risk factors for sepsis" have previously been shown to be younger [3] which may affect the capacity to use means of transportation other than the ambulance, but these speculations remain to be investigated.

\section{Reflections on observed differences between patients arriving by EMS vs by non-EMS and clinical implementation of the results}

Several factors are thought to contribute to the observed differences in keyword prevalence based on mode of arrival. We do not believe that the arrival mode per se exhibits causality on the presentation but rather that the observed differences reflect that patients arriving by EMS are older and have a higher prevalence of severe sepsis as compared with patients arriving by other means. This is supported by the stratification analyses showing that "abnormal circulation," "acute altered mental status," and "decreased mobility" did not remain significantly more frequent among EMS patients and "risk factors for sepsis" did not remain significantly more frequent among non-EMS patients when stratified for sepsis severity, indicating that differences in sepsis severity accounts for the observed differences for these keywords between EMS vs non-EMS patients.

The observed differences between septic EMS vs non-EMS patients support the principle of adapting sepsis screening tools to the population where they are planned to be implemented; in this case, the EMS vs the ED, and can be exemplified as a screening tool applied in the EMS may include variables, e.g., "abnormal circulation," "abnormal breathing," "acute altered mental status," and "decreased mobility," while a screening tool proposed to be used for "walk-in" ED patients may include other variables such as "pain" and "risk factors for sepsis."

Nevertheless, despite these observed differences, we would like to emphasize that most keywords demonstrated a similar distribution regardless of mode of arrival and the most prevalent keywords related to sepsis presentation in the current study confirm prior results from the prehospital $[3,15]$ and ED settings [13].

There are several limitations to the current study.

The definition of sepsis based on ICD-code can be questioned, as it is well known that identification of septic patients based on ICD codes leads to an underestimation of the true number of septic patients [17] and hence, there is a risk that the study sample may not be representative of all ED patients with sepsis. Inclusion based on ICD-code sepsis may involve a selection of the most severely ill septic patients. However, the method has been used in large epidemiological studies of sepsis [18] and is the only realistic method for larger registry studies.

Furthermore, the current study was a retrospective study with the inherent limitations of missing data. The prevalence of keywords was based on documented observations in ED records. Documentation may depend on various factors such as inter-individual variation among ED personnel and ED workload. Many of the keywords represent symptoms, and the identification of symptoms requires a thorough history taking by the ED doctor in addition to a communicable patient.

Multiple comparisons were performed, with the inherent risk of inferring type I errors. Therefore, the level of significance was adjusted by applying a Bonferroni correction. However, the Bonferroni correction is excessively strict with the inherent risk of inferring type II errors [19]. Hence, although erring on the side of caution, this may have resulted in true differences being regarded as non-significant.

Furthermore, when comparing the prevalence of especially primary keywords, the number of patients in the compared groups was few and hence the results must be interpreted with caution and need to be confirmed in larger samples.

Finally, the current study is a single center study which may limit the generalizability of the results. However, patients were included over a period of 1 year which enables the seasonal variation of sepsis to be accounted for. In addition, the study setting was the largest ED in Scandinavia at the time [9].

\section{Conclusions}

The distribution of most keywords related to sepsis presentation was similar irrespective of mode of arrival, however, some differences were present. Keywords "abnormal breathing," "abnormal circulation," "acute altered mental status," and "decreased mobility" were more common among patients arriving by EMS while "pain" and "risk factors for sepsis" were more common among patients arriving by means other than EMS. The results indicate that septic patients arriving to the ED via EMS are older and more often have severe sepsis. This information may be useful in clinical decision tools or sepsis screening tools but needs to be evaluated in prospective studies.

\section{Abbreviations}

EMS: Emergency medical services; ED: Emergency department;

ICD: International Classification of Diseases; HCAl: Healthcare-associated infection; SPSS: Statistical Package for the Social Sciences; IQR: Interquartile range 


\section{Supplementary Information}

The online version contains supplementary material available at https://doi. org/10.1186/s12245-021-00396-z.

Additional file 1: (PDF). Definition of severe sepsis.

Additional file 2: (PDF). Prevalence of primary keywords. The prevalence of primary keywords in the entire sample of septic patients presenting to Södersjukhuset's emergency department during 2013 and prevalence based on mode of arrival.

Additional file 3: (PDF). Prevalence of combined keywords. The prevalence of combined keywords in the entire sample of septic patients presenting to Södersjukhuset's emergency department during 2013 and prevalence based on mode of arrival.

Additional file 4: (PDF). Prevalence of keywords exceeding 20\% based on mode of arrival and age group. A comparison of prevalence of all keywords* exceeding 20\% among septic patients presenting to Södersjukhuset's emergency department during 2013, based on mode of arrival AND age group.

Additional file 5: (PDF). Prevalence of keywords exceeding 20\% based on mode of arrival and gender. A comparison of prevalence of all keywords* exceeding 20\% among septic patients presenting to Södersjukhuset's emergency department during 2013, based on mode of arrival AND gender.

Additional file 6: (PDF). Prevalence of keywords exceeding 20\% based on mode of arrival and sepsis severity. A comparison of prevalence of all keywords* exceeding 20\% among septic patients presenting to Södersjukhuset's emergency department during 2013, based on mode of arrival AND sepsis severity.

\section{Acknowledgements}

We would like to thank Stockholm city council, the Section of Emergency Medicine, Södersjukhuset, and Örebro University for funding this study.

\section{Authors' contributions}

UW was responsible for the study concept and design and contributed to the analysis and interpretation of the data and the drafting of the manuscript. AS and JS were responsible for requisition of data and EL performed the data analyses and contributed to the manuscript. HP had the principal responsibility for critical revision of the statistical analyses and contributed to the manuscript. LK has participated in the study conception and design, interpretation of the data, drafting of the manuscript, and critical revision of the manuscript for important scientific intellectual content. The authors read and approved the final manuscript.

\section{Funding}

This study was supported by grants from Stockholm city council, the Section of Emergency Medicine, Södersjukhuset, and Örebro University. The funders did not interfere neither in the interpretation of data nor in writing the manuscript. Open Access funding provided by Örebro University.

\section{Availability of data and materials}

The data that support the findings of this study are available from Örebro University, but restrictions apply to the availability of these data, which were used under license for the current study, and so are not publicly available. Data are however available from the authors upon reasonable request and with permission from Örebro University.

\section{Declarations}

Ethics approval and consent to participate

The study received approval from the Stockholm Regional Ethical Review Board (reference number 2012/1288-31/3)

\section{Consent for publication}

Not applicable.

\section{Competing interests}

All authors declare that they have no conflicting interests. UW and LK are members of the Swedish national working group for sepsis and LK is chair of the Swedish national working group for emergency medicine.

\section{Author details}

'Department of Clinical Science and Education, Karolinska Institutet, Söderssjukhuset, Sjukhusbacken 10, 11883 Stockholm, Sweden. ${ }^{2}$ Fisksätra Vårdcentral (Primary Health Care Center), Fisksätra torg 20, 13341 Saltsjöbaden, Sweden. ${ }^{3}$ Department of Medical Sciences, Örebro University, Campus USÖ, Södra Grev Rosengatan 32, 70112 Örebro, Sweden.

${ }^{4}$ Department of Surgery, Sankt Göran Hospital, Sankt Göransplan 1, 11219 Stockholm, Sweden. ${ }^{5}$ Department of Urology, Linköping University Hospital 58185 Linköping, Sweden. ${ }^{6}$ Department of Emergency Medicine, Örebro University Hospital, Södra Grev Rosengatan 18, 70362 Örebro, Sweden.

Received: 18 February 2021 Accepted: 12 November 2021

Published online: 20 December 2021

\section{References}

1. Singer M, Deutschman CS, Seymour CW, Shankar-Hari M, Annane D, Bauer $M$, et al. The third international consensus definitions for sepsis and septic shock (Sepsis-3). Jama. 2016;315(8):801-10. https://doi.org/10.1001/jama.201 6.0287 .

2. Prescott HC, Angus DC. Enhancing recovery from sepsis: a review. Jama. 2018;319(1):62-75. https://doi.org/10.1001/jama.2017.17687.

3. Wallgren UM, Bohm KEM, Kurland L. Presentations of adult septic patients in the prehospital setting as recorded by emergency medical services: a mixed methods analysis. Scand J Trauma Resuscitation Emer Med. 2017;25(1):23.

4. Long B, Koyfman A. Clinical mimics: an emergency medicine-focused review of sepsis mimics. J Emer Med. 2017;52(1):34-42. https://doi.org/10.1016/j. jemermed.2016.07.102

5. Bayer O, Schwarzkopf D, Stumme C, Stacke A, Hartog CS, Hohenstein C, et al. An early warning scoring system to identify septic patients in the prehospital setting: the PRESEP score. Acad Emer Med. 2015;22(7):868-71. https://doi.org/10.1111/acem.12707.

6. Singer AJ, Taylor M, Domingo A, Ghazipura S, Khorasonchi A, Thode HC Jr et al. Diagnostic characteristics of a clinical screening tool in combination with measuring bedside lactate level in emergency department patients with suspected sepsis. Acad Emery Med. 2014;21(8):853-7. https://doi.org/1 0.1111 /acem.12444

7. Suffoletto B, Frisch A, Prabhu A, Kristan J, Guyette FX, Callaway CW. Prediction of serious infection during prehospital emergency care. Prehospital Emer Care. 2011;15(3):325-30. https://doi.org/10.3109/1090312 7.2011 .561411

8. Femling J, Weiss S, Hauswald E, Tarby D. EMS patients and walk-in patients presenting with severe sepsis: differences in management and outcome. Southern Med J. 2014;107(12):751-6. https://doi.org/10.14423/SMJ. 0000000000000206

9. About Södersjukhuset: Södersjukhuset AB; 2019 [updated 2017; cited 20196 April]. Available from: http://www.sodersjukhuset.se/Om-SOS/.

10. Healthcare-Associated Infection [Internet]. The national board of health and welfare. 2015 [cited 23 December 2015]. Available from: http://termbank. socialstyrelsen.se/showterm.php?fTid=445

11. Levy MM, Fink MP, Marshall JC, Abraham E, Angus D, Cook D, et al. 2001 SCCM/ESICM/ACCP/ATS/SIS international sepsis definitions conference. Crit Care Med. 2003;31(4):1250-6. https://doi.org/10.1097/01.CCM.0000050454.01 978.3B

12. Wallgren UM, Castren M, Svensson AE, Kurland L. Identification of adult septic patients in the prehospital setting: a comparison of two screening tools and clinical judgment. Eur J Emer Med. 2014;21(4):260-5. https://doi. org/10.1097/MEJ.0000000000000084.

13. Edman-Waller J, Ljungstrom $L$, Jacobsson $G$, Andersson $R$, Werner $M$. Systemic symptoms predict presence or development of severe sepsis and septic shock. Infect Dis (London, England). 2016;48(3):209-14

14. Gille-Johnson P, Hansson KE, Gardlund B. Severe sepsis and systemic inflammatory response syndrome in emergency department patients with suspected severe infection. Scand J Infect Dis. 2013;45(3):186-93. https://doi. org/10.3109/00365548.2012.720025. 
15. Bohm K, Kurland L, Bartholdson S, Castren M. Descriptions and presentations of sepsis - a qualitative content analysis of emergency calls. Int Emer Nurs. 2015;23(4):294-8. https://doi.org/10.1016/j.ienj.2015.04.003.

16. Downey LV, Zun LS. Pain management in the emergency department and its relationship to patient satisfaction. J Emer Trauma Shock. 2010;3(4):32630. https://doi.org/10.4103/0974-2700.70749.

17. Henriksen DP, Laursen CB, Jensen TG, Hallas J, Pedersen C, Lassen AT. Incidence rate of community-acquired sepsis among hospitalized acute medical patients-a population-based survey. Crit Care Med. 2015;43(1):1321. https://doi.org/10.1097/CCM.0000000000000611.

18. Martin GS, Mannino DM, Eaton S, Moss M. The epidemiology of sepsis in the United States from 1979 through 2000. N Engl J Med. 2003;348(16): 1546-54. https://doi.org/10.1056/NEJMoa022139.

19. Perneger TV. What's wrong with Bonferroni adjustments. BMJ (Clinical research ed). 1998;316(7139):1236-8. https://doi.org/10.1136/bmj.316.713 9.1236 .

\section{Publisher's Note}

Springer Nature remains neutral with regard to jurisdictional claims in published maps and institutional affiliations.

Ready to submit your research? Choose BMC and benefit from:

- fast, convenient online submission

- thorough peer review by experienced researchers in your field

- rapid publication on acceptance

- support for research data, including large and complex data types

- gold Open Access which fosters wider collaboration and increased citations

- maximum visibility for your research: over $100 \mathrm{M}$ website views per year

At BMC, research is always in progress.

Learn more biomedcentral.com/submissions 